\title{
Profile of Newborns Hospitalized for Maternal Fetal Infection and Having a Positive CRP in the Pediatric Department of the Gabriel Touré CHU in Bamako, Mali
}

\author{
Oumar Coulibaly ${ }^{*}$, Hawa Gouro Diall1, Guédiouma Dembélé2, Mamary Coulibaly ${ }^{1}$, \\ Fatoumata Léonie Françoise Diakité1, Lala Ndrayni Sidibé1, Leyla Maiga1, Ibrahima Ahamadou1, \\ Abdoul Karim Doumbia1, Belco Maiga1, Adama Dembelé1, Pierre Togo1, Karamoko Sacko1, \\ Mohamed Elmouloud Cissé1, Djeneba Konaté1, Fousseyni Traoré1, Aminata Doumbia1, \\ Yacouba Aba Coulibaly1', Amadou Touré1, Bourama Kané2, Issa Amadou Touré3, \\ Abdoul Aziz Diakité1, Traoré Fatoumata Dicko Traoré1, Mariam Sylla1 ${ }^{1}$ Boubacar Togo ${ }^{1}$
}

${ }^{1}$ Department of Pediatrics, CHU Gabriel Touré, Bamako, Mali

${ }^{2}$ Department of Pediatrics, Mali Hospital, Bamako, Mali

${ }^{3}$ Department of Pediatric Surgery, CHU Gabriel Touré, Bamako, Mali

Email: *cheickcoul1@live.fr

How to cite this paper: Coulibaly, O., Diall, H.G., Dembélé, G., Coulibaly, M., Diakité, F.L.F., Sidibé, L.N., Maiga, L., Ahamadou, I., Doumbia, A.K., Maiga, B., Dembelé, A., Togo, P., Sacko, K., Cissé, M.E., Konaté, D., Traoré, F., Doumbia, A., Coulibaly, Y.A., Touré, A., Kané, B., Touré, I.A., Diakité, A.A., Traoré, T.F.D., Sylla, M. and Togo, B. (2021) Profile of Newborns Hospitalized for Maternal Fetal Infection and Having a Positive CRP in the Pediatric Department of the Gabriel Touré CHU in Bamako, Mali. Open Journal of Pediatrics, 11, 684-693.

https://doi.org/10.4236/ojped.2021.114064

Received: October 21, 2021

Accepted: December 5, 2021

Published: December 8, 2021

Copyright $\odot 2021$ by author(s) and Scientific Research Publishing Inc. This work is licensed under the Creative Commons Attribution International License (CC BY 4.0).

http://creativecommons.org/licenses/by/4.0/

\section{Abstract}

Objective: Early bacterial neonatal infection (INBP) or maternofetal infection (early neonatal sepsis) remains a concern of the pediatrician due to diagnostic difficulties and its increased morbidity and mortality. No study has been done in Mali on the profile of newborns admitted for INBP with positive CRP, hence the initiation of this work with the aim of studying the epidemiological, biological and bacteriological profile of newborns with a bacterial maternal-fetal infection. Method: Longitudinal study descriptive (from 27 June to 3 September 2016) which concerned all newborns aged from 0 to 72 hours of life hospitalized for confirmed early bacterial neonatal infection with a positive C-reactive protein (CRP) in the neonatal department of the $\mathrm{CHU}$ Gabriel Touré. INBP was defined by the presence of maternal and neonatal infectious risk factors, positivity of CRP with a germ in the blood culture. Results: During the study period we included 244 newborns for probable maternofetal infection and who benefited from the CRP assay, 43 had a positive CRP, i.e. a frequency of $17.62 \%$. The sex ratio was 2.30 . The majority had a low birth weight $(<2500 \mathrm{~g})$ in $69.8 \%$ of cases. Mothers were aged 18 to 35 in $93 \%$. The majority were out of school (43.8\%) and housewives in $74.4 \%$. The main reasons for consultations were prematurity and/or low birth weight, respiratory distress and neonatal distress, i.e. $46.5 \%, 25.6 \%$ and $11.6 \%$ respec- 
tively. Among the 43 newborns with a positive CRP, the blood culture returned positive in $79.1 \%(\mathrm{n}=34)$. We deplore 2 deaths $(4.7 \%)$. The main bacteria were gram-positive cocci (Staphylococcus aureus 53.01\% and Streptococccus agalactiae $4.10 \%$ ), gram-negative bacilli (GNB) type Enterobacteriaceae (Klebsiella pneumoniae $11.25 \%$ and E. coli at 5.70\%) and non-fermentative GNBs (Pseudomonas aeruginosa 2.80\% and Acinetobacter baumannii complex 2.24\%). Conclusion: Maternal-fetal infection is a hospital pathology frequently encountered in the neonatal period. Its clinical presentation is dominated by respiratory distress, neurological disorders and low birth weight.

\section{Keywords}

Early Bacterial Neonatal Infection, Clinical Profile, Neonatal Mortality

\section{Introduction}

Neonatal mortality remains a major public health challenge in the world with 2.7 million annual deaths, eighty percent of these deaths occur in the developing world in particular sub-Saharan Africa and South and South Asia [1] [2]. Currently, neonatal bacterial infections are the third leading cause of newborn death worldwide, behind prematurity and childbirth-related mortality, and account for $10 \%$ of deaths before the age of 5 . The mortality gap between high- and low/middle-income countries may be explained by inadequate monitoring of some pregnancies, the lack of systematic screening for pre- and per-partum risk factors of INBP, and immediate postnatal surveillances of the newborn in poorly done maternity hospitals are factors that increase the morbidity and mortality of INBP in developing countries [3]. The etiology of early bacterial neonatal infections (INBP) also differs depending on the level of development. In industrialized countries, group B streptococcus (GBS) remains the predominant germ [4], despite systematic screening between the $34^{\text {th }}-35^{\text {th }}$ week of pregnancy and intrapartum antibiotic therapy in the event of colonization [5]. In developing countries, early neonatal bacterial infections (INBP) are mainly caused by multidrug-resistant gram-negative bacilli with increased neonatal mortality rate, particularly Escherichia coli and Klebsiella spp. [3] [6] [7] [8]. This is due to the lack of financial means for access to the best-indicated antibiotics in these developing countries [9]. Specific and sensitive early markers, with a high negative predictive value, would therefore be particularly appreciated in neonatal medicine. The neonatologist will mainly use the complete blood count, C-reactive protein (CRP) by repeating the assays and sometimes the blood culture. In the neonatal department of the Pediatrics Department of the CHU Gabriel Touré, neonatal infection is the third leading cause of hospitalization and death after prematurity and perinatal asphyxia [10]. In the African context, knowledge of an epidemiological and clinical profile of confirmed neonatal bacterial infection is necessary to ensure rapid treatment, especially in regions where the performance of con- 
firmatory diagnostic examinations is not possible. where the initiation of this study on the epidemiological and clinical profile of newborns admitted for maternofetal infection with a positive CRP in order to improve our practice.

\section{Material and Methods}

The study took place in the neonatology service of the pediatrics department of the CHU Gabriel Touré in Bamako. It is the only national reference service for the care of newborns in Mali. We carried out a prospective cross-sectional study that focused on the clinical and biological characteristics of hospitalized newborns from June 27 to September 3, 2016 ((2 months and 8 days)). Newborns less than or equal to 72 hours hospitalized for suspected early neonatal sepsis (maternal and neonatal infectious risk factors and/or clinical signs) in the neonatal service of the pediatric department of the CHU Gabriel Touré in Mali have been included in this study. The suspicion of INBP was based on the presence of maternal and neonatal infectious risk factors and/or clinical signs. The following immediate pre, per and postpartum infectious risk factors were retained: rupture of membranes greater than or equal to 18 hours, rupture of the water bag before 37 weeks, maternal fever greater than $38^{\circ} \mathrm{C}$ in 48 hours before or after childbirth, maternal genital and/or urinary tract infection in the last month of pregnancy, tinted or meconium amniotic fluid, unexplained fetal distress or prematurity, twin with confirmed BNI, respiratory problems and/or unexplained neonatal heart disease. When at least one of these factors was present, a blood culture was performed on admission, as well as the C-Reactive Protein (CRP) at the 12 hours of life and the complete blood count $(\mathrm{CBC})$ at the $24^{\text {th }}$ hour of life. The blood sample for blood culture was inoculated on fresh sheep blood agar (5\%) and on cooked blood agar supplemented with Polyvitex. The incubation was done for 24 to 48 hours under $5 \% \mathrm{CO}_{2}$. An antibiogram by diffusion in agar medium was carried out on all the isolated strains. Partial results of the fresh state (presence or absence of leukocytes and bacteria) were communicated to the clinicians after 24 to 48 hours to allow them to orient their therapeutic approach. Thus, the following operational definitions have been adopted:

- A confirmed case of INBP: any newborn baby at most three days old presenting one or more clinical and/or biological signs with positive blood culture.

- A suspected case of INBP: any newborn with at least one infectious criterion in the history associated with one or more clinical and/or biological signs with negative blood culture.

\section{Data processing}

Data were entered and analyzed on SPSS software.

\section{Results}

During the study period, we included 244 newborns for probable maternofetal infection and who benefited from the CRP assay, 43 had a positive CRP, i.e. a frequency of $17.62 \%$. There were 30 male (57.7\%) and 13 female (42.3\%) new- 
borns, for a sex ratio of 2.30. The majority of newborns ( $\mathrm{n}=68$ [93\%]) were admitted within the first 24 hours of life (Figure 1), the majority had a low birth weight $(<2500 \mathrm{~g})$ in $69.8 \%$ of cases. In $39.5 \%$ of cases the newborns were referred to the ambulance. Mothers were aged 18 to 35 in $93 \%$. They were mostly out of school (43.8\%), primary level (27.2\%), secondary (17.6\%) and housewives in $74.4 \%$. The majority of mothers had less than 4 ANC (67.4\%) and $32.6 \%$ had 4 or more ANC. Vaginal delivery was the most frequent (81.4\%), the Apgar score at the first minute was $>7$ in $27.8 \%$ of cases and unspecified $(62.8 \%)$, at the fifth minute it was $>7$ in $39.5 \%$ of cases and not specified $(60.5 \%)$. The vast majority of newborns made the consultation within the first 24 hours of life (86\%). The ambulance was used as a means of transport in only $39.5 \%$ of cases (Figure 2). The main reasons for consultations were prematurity and/or low birth weight, respiratory distress and neonatal distress, i.e. $46.5 \%, 25.6 \%$ and $11.6 \%$ respectively (Figure 3 ). Anamnestic risk factors for infection were dominated by prematurity $<35$ weeks, maternal fever $\geq 38^{\circ} \mathrm{C}$, unexplained fetal distress, opening

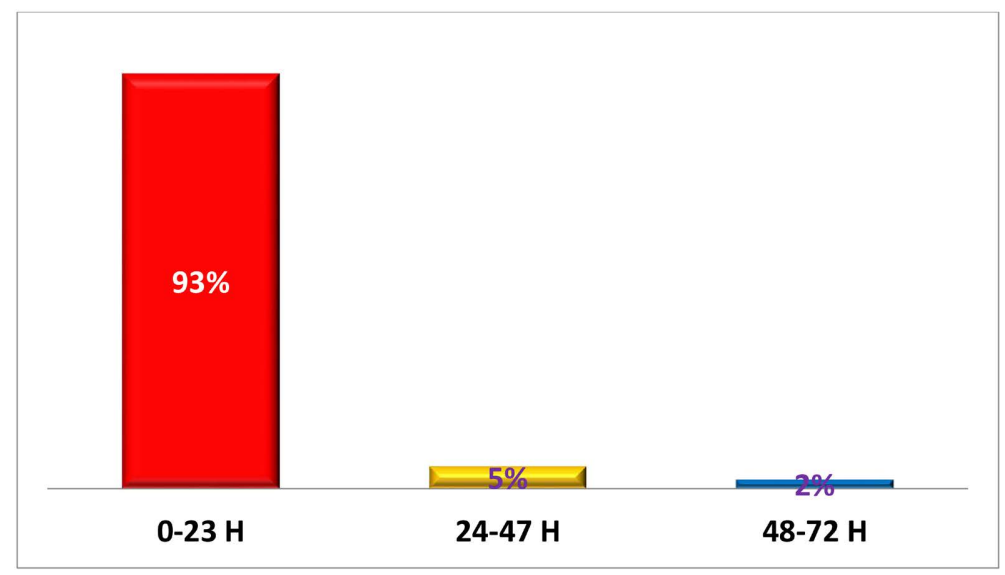

Figure 1. Age at admission.

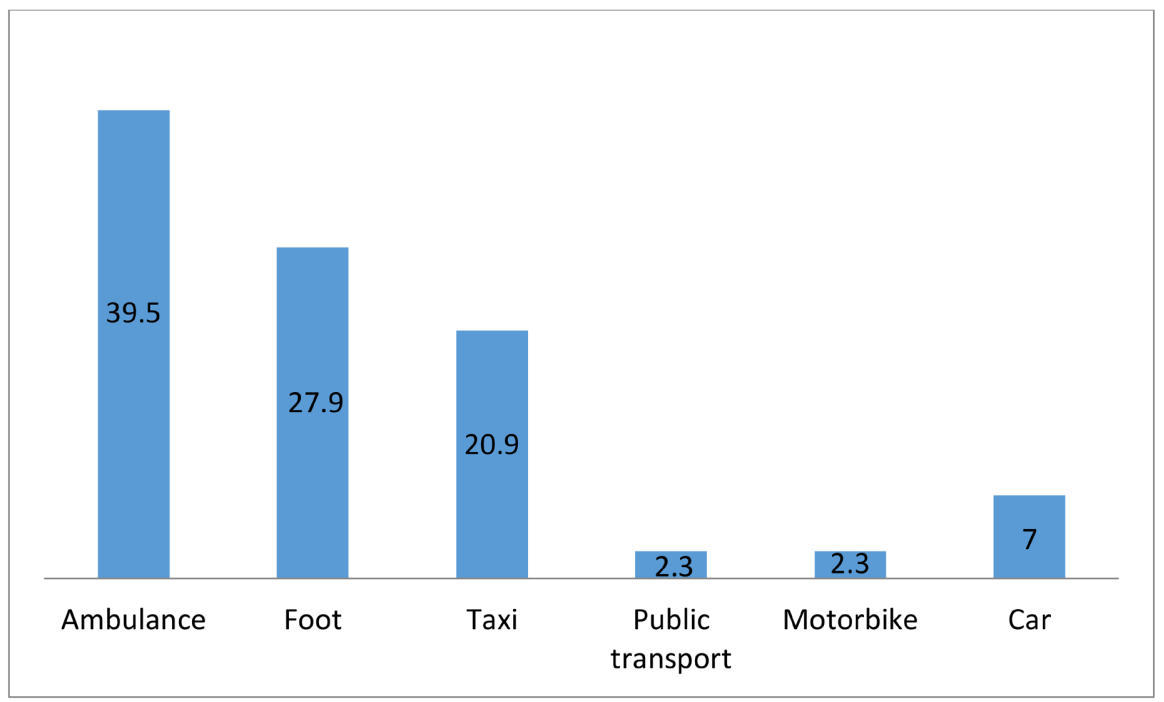

Figure 2. Means of transport. 
of the water bag $>18$ hours, and fetid or meconium amniotic fluid, respectively $32.6 \%, 20.9 \%, 20.9 \%, 11.6 \%, 11.6 \%$ (Table 1). Among the 43 newborns with a positive CRP, the blood culture returned positive in $79.1 \%(\mathrm{n}=34)$. We deplore

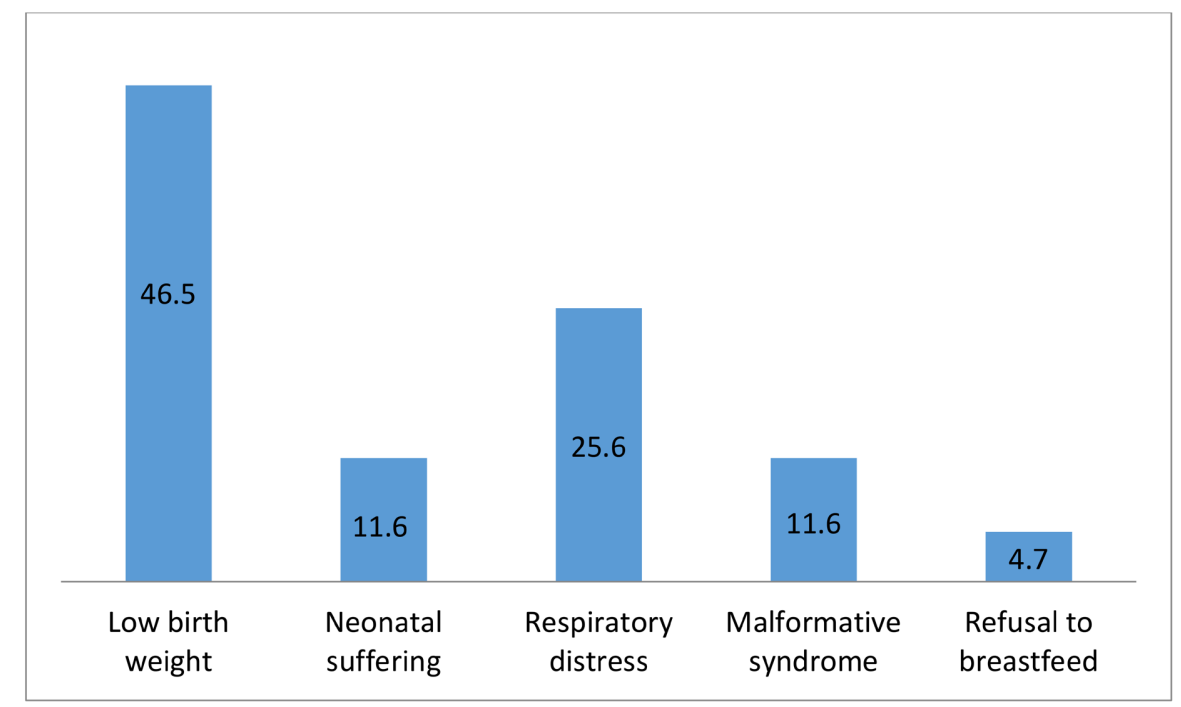

Figure 3. The main reasons for consultation.

Table 1. Anamnestic risk factors for maternal-fetal infection.

\begin{tabular}{|c|c|c|}
\hline Criteria & Frequency $(n=43)$ & Percentage (\%) \\
\hline \multicolumn{3}{|l|}{ Major anamnestic criteria for infection } \\
\hline Prematurity $<35$ SA & 14 & 32.6 \\
\hline Maternal temperature $\geq 38^{\circ}$ & 9 & 20.9 \\
\hline Rupture of the water pocket before $37 \mathrm{SA}$ & 3 & 7 \\
\hline Opening of the water bag $\geq 18 \mathrm{~h}$ & 5 & 11.6 \\
\hline Twin diagnosed with maternal fetal infection & 0 & 0 \\
\hline Clinical picture of chorioamnionitis & 1 & 2.3 \\
\hline \multicolumn{3}{|l|}{ Minor anamnestic criteria for infection } \\
\hline Unexplained fetal distress & 9 & 20.9 \\
\hline Tinted or meconial amniotic fluid & 5 & 11.6 \\
\hline Opening of the water bag $\geq 12 \mathrm{~h}$ & 0 & 0 \\
\hline Premature 35 weeks & 2 & 4.7 \\
\hline \multicolumn{3}{|l|}{ Other criteria } \\
\hline Fetid leucorrhoea & 16 & 37.2 \\
\hline Dysuria & 6 & 14 \\
\hline Urination burns in the last trimester & 10 & 23.3 \\
\hline Maternal genitourinary infection & 2 & 4.7 \\
\hline Home birth & 0 & 0 \\
\hline
\end{tabular}


2 deaths (4.7\%). The main bacteria were gram-positive cocci (Staphylococcus aureus $53.01 \%$ and Streptococccus agalactiae 4.10\%), gram-negative bacilli (GNB) type Enterobacteriaceae (Klebsiella pneumoniae $11.25 \%$ and E. coli at 5.70\%) and non-fermentative GNBs (Pseudomonas aeruginosa 2.80\% and Acinetobacter baumannii complex 2.24\%).

\section{Discussion}

Bacterial neonatal infection is the third cause of hospitalization at CHU Gabriel Touré with a frequency varying from $16.2 \%$ to $22.5 \%$ during the $2008-2012$ five-year term [10]. The 2016 study carried out on confirmed BNIs revealed a frequency of $11.04 \%$. Prior to 2008 , the true frequency of INBP could not be appreciated. According to international literature, INBP is a common cause of hospitalization and is responsible for one-third of perinatal mortality [11]. In the present study, the overwhelming majority (93\%) of hospitalized newborns were less than 24 hours old and $72.9 \%$ of outborn transfers were medicalized in only $39.5 \%$. We know that improving the referral system for newborns leads to a reduction in neonatal morbidity and mortality [12]. In our study, seven out of ten newborns were premature and/or hypotrophic (69.8\%). The frequency of premature babies was higher than that generally found in the literature, between 6 and $51.4 \%$ [13] [14]. This high rate of prematurity could be linked to illiteracy (63.5\%), insufficient antenatal consultations and poor qualities, the existence of major maternal infectious risk factors. However, according to Vial-Courmont et al., prematurity increases the risk of infection and when neonatal infection occurs, it is severe from the outset and may be responsible for heavy mortality and significant neurological sequelae. The same authors noted that infection is six times more frequent in feverish childbirth [15]. In the current study, one in five mothers (20.9\%) was feverish during childbirth. In our series, other anamnestic criteria were used; fetid leucorrhoea (37.2\%), prematurity $<35$ weeks $(32.6 \%)$, urination burns during the last trimester (23.3\%), unexplained fetal distress (20.9\%), of the water bag $\geq 18 \mathrm{~h}$ and the tinted or meconium amniotic fluid (11.6\% each) (Table 1). NF Coly and Col in Dakar had retained a predominance of the concept of tinted amniotic fluid, i.e. $30 \%$, followed by prematurity $18 \%$ and premature rupture of membranes 12\% [16]. In Togo, the study by Balaka [17] found as anamnestic criteria, meconium amniotic fluid (24\%), rupture of membranes for more than 12 hours (21\%) and unexplained prematurity (19\%). On the other hand, the signs in front of the clinical picture are respiratory and neurological distress of $40 \%$ and $48 \%$ respectively. For Nouaili, [18] respiratory disorders predominated in $36.1 \%$ of cases, followed by neurological disorders (13.2\%). A newborn baby presented with oral thrush on admission. In our work, respiratory distress represented 25.6\%. Studies [19] [20] have shown that CRP is a key tool in the management of newborns suspected of MFI, with a sensitivity of $80 \%$ to $90 \%$. The role of CRP in the duration of antibiotic treatment has also been studied. Serial CRP measurements may be useful in monitoring response to 
treatment of infected newborns, determining the duration of antibiotic therapy and to recognize possible complications [21] [22]. In a cohort of 60 newborns with precocious sepsis, Ehl et al. [23] demonstrated that, after initiation of antibiotic treatment, CRP increased further, peaking and then subsequently decreased after 16 hours, with a CRP value returning to normal again, which may indicate that the duration of the antibiotic treatment has been sufficient to allow the antibiotics to be stopped, provided the clinical condition of the child and the results of the tests bacteriological came back negative. Thus, CRP has been proposed as a key parameter in the decision to guide the duration of antibiotic therapy [24]. However, CRP was not the only endpoint evaluated in these studies. In fact, other criteria are included in the decision of whether to stop antibiotics or not, namely, the clinical condition and the results of blood cultures. The contribution of bacteriology to deciding on the duration of antibiotic therapy is limited by the low rate of positive blood cultures, which varies in the literature from $2 \%$ to $10.2 \%$ [25] [26]. In our study, bacteriology was positive in $79.10 \%$ of hospitalized newborns. In the study by Franz et al. [22] concerning nosocomial bacterial infections, antibiotic therapy has only been started in symptomatic newborns with an elevated CRP, allowing treatment to be reduced to $71 \%$ of symptomatic newborns; the positive blood culture rate was $10 \%$. In the prospective study by the same author, published in 2004 [26], only 13 newborns suspected of bacterial infection among 1291 had a positive blood culture. Variations in frequency could be explained by the different methodologies used. In our study, the bacterial ecology found during these INBP by transmission of maternal origin in utero or during childbirth is similar to that usually mentioned in another study of the West African sub-region with predominance of Staphylococcus aureus [27]. This predominance of Staphylococcus aureus during INBP could be due to the infection or colonization of many pregnant women by this bacterium which is mostly found during pregnancy according to Balaka et al. and not necessarily in connection with the conditions of precarious asepsis in neonatal units in Africa south of the Sahara [27]. Staphylococci and enterobacteria isolated in samples from pathological pregnancies are responsible for manifestations such as chorioamnionitis, prematurity with severe neonatal infections [15]. This can be illustrated by this work on bacterial genital carriage in the last trimester of pregnancy, which induced lesions such as endocervicitis (25\%) and vaginosis (19.7\%) and be the cause of the INBP [28]. In Morocco [29], it is above all certain Gram-negative bacilli that are isolated during MFI. They are $E$. coli, Klebsiella pneumoniae and Enterobacter. In some western countries, we note the emergence of GNBs which represented $78 \%$ of the germs isolated (Klebsiella Pneumoniae: 36\% and Escherichia coli: 11\% versus Group B Streptococcus: 4.5\%) [29]. In the present study, we note the absence of Listeria monocytogenes. This could be explained by the lack of testing for bacteria in the cerebrospinal fluid in this work. In Mali, between 2003 (nosocomial and community germs) and 2016 (community germs), there was the emergence of new 
strains such as Streptococcus agalactiae, Escherichia coli, Acinetobacter baumannii complex, and Klebsiella pneumoniae [29] [30].

\section{Conclusion}

At the end of our study, it emerges that maternofoetal infection is a hospital pathology frequently encountered in the neonatal period. Its clinical presentation is dominated by respiratory distress, neurological disorders and low birth weight. The bacterial ecology is dominated by Staphylococci and Enterobacteriaceae ( $K$. pneumoniae and $E$. coli). The evolution is favorable in $95.3 \%$ of cases and the rate of neonatal death due to IMF is $4.7 \%$.

\section{Conflicts of Interest}

The authors declare no conflicts of interest regarding the publication of this paper.

\section{References}

[1] Liu, L., Oza, S., Hogan, D., et al. (2016) Global, Regional, and National Causes of Under-5 Mortality in 2000-15: An Updated Systematic Analysis with Implications for the Sustainable Development Goals. Lancet, 388, 3027-3035. https://doi.org/10.1016/S0140-6736(16)31593-8

[2] Waters, D., Jawad, I., Ahmad, A., et al. (2011) Etiology of Community-Acquired Neonatal Sepsis in Low and Middle Income Countries. Journal of Global Health, 1, 154-170.

[3] Lawn, J.E., Kerber, K., Enweronu-Laryea, C. and Cousens, S. (2010) 3.6 Million Neonatal Deaths What Is Progressing and What Is Not? Seminars in Perinatology, 34, 371-386. https://doi.org/10.1053/j.semperi.2010.09.011

[4] Edmond, K.M., Kortsalioudaki, C., Scott, S., et al. (2012) Group B Streptococcal Disease in Infants Aged Younger than 3 Months: Systematic Review and Meta-Analysis. Lancet, 379, 547-556. https://doi.org/10.1016/S0140-6736(11)61651-6

[5] Weston, E.J., Pondo, T., Lewis, M.M., et al. (2011) The Burden of Invasive Early-Onset Neonatal Sepsis in the United States, 2005-2008. Pediatric Infectious Disease Journal, 30, 937-941. https://doi.org/10.1097/INF.0b013e318223bad2

[6] Lubell, Y., Turner, P., Ashley, E.A., et al. (2011) Susceptibility of Bacterial Isolates from Community-Acquired Infections in Sub-Saharan Africa and Asia to Macrolide Antibiotics. Tropical Medicine \& International Health, 16, 1192-1205. https://doi.org/10.1111/j.1365-3156.2011.02837.x

[7] Huynh, B.T., Padget, M., Garin, B., et al. (2015) Burden of Bacterial Resistance among Neonatal Infections in Low Income Countries: How Convincing Is the Epidemiological Evidence? BMC Infectious Diseases, 15, Article No. 127. https://doi.org/10.1186/s12879-015-0843-x

[8] Laxminarayan, R., Matsoso, P., Pant, S., et al. (2016) Access to Effective Antimicro bials: A Worldwide Challenge. Lancet, 387, 168-175. https://doi.org/10.1016/S0140-6736(15)00474-2

[9] Ganatra, H.A. and Zaidi, A.K. (2010) Neonatal Infections in the Developing World. Seminars in Perinatology, 34, 416-425. https://doi.org/10.1053/j.semperi.2010.09.004 
[10] Dicko-Traoré, F., Sylla, M., Traoré, Y., Traoré, A., Diall, H., Diakité, A.A., et al. (2014) Mali's National Reference Neonatal Unit: State of Play. Public Health, 26, 115-121. https://doi.org/10.3917/spub.137.0115

[11] Aujard, Y. and Bottineau, M.C. (2015) Classification and Pathophysiology of Neonatal Infections: Neonatal Infections. Diagnosis and Therapy, 22, 1-7.

[12] Dicko Traoré, F., Sylla, M., Diakité, A.A., Soilihi, A., N’Diaye, M.D., Traoré, B., et al. (2010) Problem of Neonatal Transfer to the Pediatric Department of CHU Gabriel Touré. Mali Medical, 25, 25-28.

[13] Bhat, Y.R., Lewis, L.E. and Vandana, K.E. (2011) Bacterial Isolates of Early-Onset Neonatal Sepsis and Their Antibiotic Susceptibility Pattern between 1998 and 2004: An Audit from a Center in India. Italian Journal of Pediatrics, 37, Article No, 32. https://doi.org/10.1186/1824-7288-37-32

[14] Chiabi, A., Djoupomb, M., Mah, E., Nguefack, S., Mbuagbaw, L., Zafack, J., et al. (2011) The Clinical and Bacteriological Spectrum of Neonatal Sepsis in a Tertiary Hospital in Yaounde Cameroon. Iranian Journal of Pediatrics, 21, 441-448.

[15] Vial-Courmont, M., Arnaud, F., Guibert, M. and Lacaze-Masmonteil, T. (2000) Epidemiology of Maternal-Fetal Bacterial Infection: Experience of a Perinatal Center. Journal de Pédiatrie et de Puériculture, 13, S4-S9. https://doi.org/10.1016/S0987-7983(00)80112-7

[16] Coly, N.F., Diallo, F., Bass, I., et al. (2017) Contribution of C-Reactive Protein in the Diagnosis of Neonatal Infections. Health Cames, 5.

[17] Balaka, B., Monkoungou, B., Matey, K., Napo-Bitantem, S., Kessie, K. and Assimadi, K. (2004) Neonatal Sepsis: Bacteriological and Evolutionary Aspects at the University Hospital of Lomé, Togo. Bulletin de la Société de Pathologie Exotique, 97, 97-99.

[18] Nouaili, E.B.H., Harouni, M., Chaouachi, S., Sfar, R. and Marrakchi, Z. (2008) Bacterial Maternal-Fetal Infection: Retrospective Study of 144 Cases. Medical Tunisia, 86, 136-169.

[19] Enguix, A., Rey, C., Concha, A., Medina, A., Coto, D. and Dieguez, M.A. (2001) Comparison of Procalcitonin with C-Reactive Protein and Serum Amyloid for the Early Diagnosis of Bacterial Sepsis in Critically Ill Neonates and Children. Intensive Care Medicine, 27, 211-215. https://doi.org/10.1007/s001340000709

[20] Ng, P.C., Li, G., Chiu, K.M., Chu, W.C.W., Li, K., Wong, R.P.O., et al. (2004) Neutrophil CD64 Is a Sensitive Diagnostic Marker for Early Onset Neonatal Infection. Pediatric Research, 56, 769-803. https://doi.org/10.1203/01.PDR.0000142586.47798.5E

[21] Kawamura, M. and Nishida, H. (1995) The Usefulness of Serial C-Reactive Protein Measurement in Managing Neonatal Infection. Acta Paediatrica, 84, 10-13. https://doi.org/10.1111/j.1651-2227.1995.tb13475.x

[22] Franz, A.R., Steinbach, G., Kron, M. and Pohlandt, F. (1999) Reduction of Unnecessary Antibiotic Therapy in Newborn Infants Using Interleukin-8 and C-Reactive Protein as Markers of Bacterial Infections. Pediatrics, 104, 447-453.

https://doi.org/10.1542/peds.104.3.447

[23] Ehl, S., Gehring, B. and Pohlandt, F. (1999) A Detailed Analysis of Changes in Serum C-Reactive Protein Levels in Neonates Treated for Bacterial Infection. European Journal of Pediatrics, 158, 238-242. https://doi.org/10.1007/s004310051058

[24] Hofer, N., Zacharias, E., Müller, W. and Resch, B. (2012) An Update on the Use of C-Reactive Protein in Early-Onset Neonatal Sepsis: Current Insights and New Tasks. Neonatology, 102, 25-36. https://doi.org/10.1159/000336629

[25] Seboui, H. and Tunisian Neonatal Study Group (2005) Management of Newborns 
Suspected of Maternal-Fetal Infection. Maghrebine Journal of Pediatrics, 15, 104-106.

[26] Franz, A.R., Bauer, K., Schalk, A., Garland, S., Bowman, E.D., Rex, K., et al. (2004) Measurement of Interleukin-8 in Combination with C-Reactive Protein Reduced Unnecessary Antibiotic Therapy in Newborn Infants: A Multicenter, Randomised, Controlled Trial. Pediatrics, 114, 1-8. https://doi.org/10.1542/peds.114.1.1

[27] Folquet-Amorissani, M., Dainguy, M.E., Diomande, D., Kouakou, C., Kamenan, M., Mbengue Gbonon, V.C., et al. (2016) Update of the Profile of Bacterial Infections of Newborns at Cocody University Hospital in Abidjan. Journal of Pediatrics and Childcare, 29, 8-14. https://doi.org/10.1016/j.jpp.2015.10.002

[28] Chemsi, M. and Benomar, S. (2015) Infections bactériennes néonatales précoces. Journal de pédiatrie et de puériculture, 28, 29-37.

https://doi.org/10.1016/j.jpp.2014.10.005

[29] Macharashvili, N., Kourbatova, E., Butsashvili, M., Tsertsvadze, T., McNutt, L.A. and Leonard, M.K. (2009) Etiology of Neonatal Blood Stream Infections in Tbilisi, Republic of Georgia. International Journal of Infectious Diseases, 13, 499-505. https://doi.org/10.1016/j.ijid.2008.08.020

[30] Sylla, M., Folquet-Amorissani, M., Dicko-Traoré, F., Chokoteu, Y.D., Sidibé, T. and Kéita, M.M. (2006) Neonatal Bacterial Infections in the Pediatric Service of Bamako: Clinical and Etiological Aspects. Medical Guinea, 52, 63-68. 